\title{
Le point poumon
}

\section{The lung point}

\section{T. Schmutz $\cdot$ M. Hoffmann $\cdot$ E. Andre $\cdot$ F. Braun}

Reçu le 30 novembre 2012 ; accepté le 31 janvier 2013

(C) SFMU et Springer-Verlag France 2013

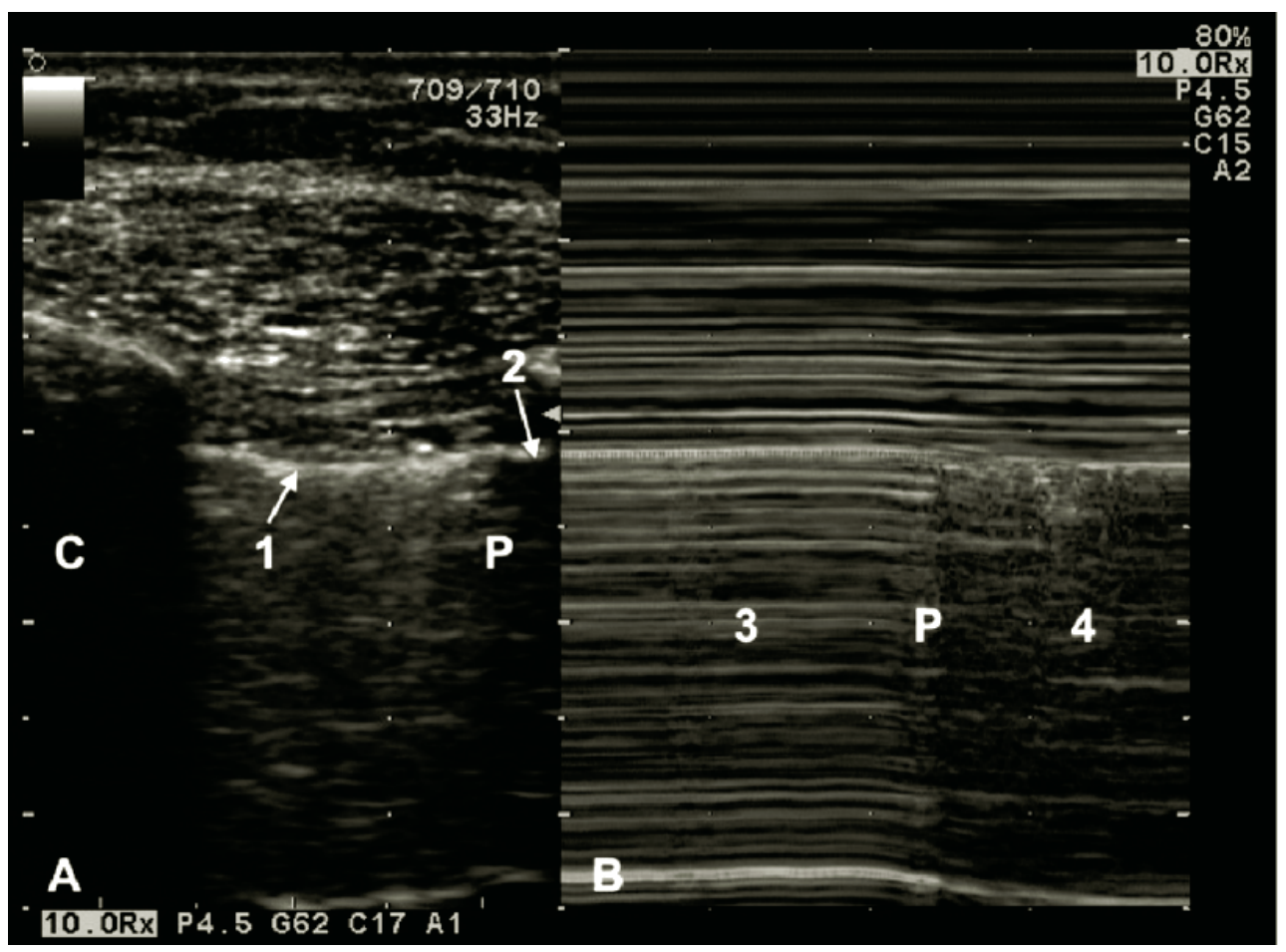

Fig. 1 Echographie pulmonaire (mode 2D et TM) d'un pneumothorax: mise en évidence du point poumon.

Le point poumon (P) est affirmé par la visualisation en mode 2D (A) d'une ligne pleurale avec une zone de glissement (1) et une zone de non glissement (2) entre les cônes d'ombre des côtes (C), puis en mode TM (B) par une alternance d'un profil de ligne A exclusives (3) avec un signe du « bord de mer» (4)

Une patiente âgée de 42 ans est adressée aux urgences pour suspicion de pneumothorax. La radiographie thoracique de face est peu contributive. Une échographie pulmonaire est réalisée afin de préciser le diagnostic. Le pneumothorax est suspecté par l'abolition du glissement pleural (mode 2D), un profil de lignes A exclusives (mode TM). La mise en évidence du point poumon (Fig. 1) permet d'affirmer avec cer-

T. Schmutz $(\bowtie) \cdot$ M. Hoffmann $\cdot$ E. Andre $\cdot$ F. Braun Service des urgences, Samu-Smur, CHR Metz-Thionville, 1, allée du château, F-57085 Ars-Laquenexy, France e-mail : t.schmutz@chr-metz-thionville.fr titude le diagnostic (spécificité $100 \%$; sensibilité $66 \%$ ) [1]. Il correspond à l'accolement du poumon à la paroi lors de l'inspiration en cas de pneumothorax partiel, il est donc souvent visualisé dans les zones latérales du thorax chez un sujet en décubitus dorsal.

\section{Référence}

1. Lichtenstein D, Mezière G, Biderman P et al (2000) The "lung point": an ultrasound sign specific to pneumothorax. Intensive Care Med 26:1434-1440 